\title{
A Cone-beam Computed Tomographic Evaluation of Removing Root Canal Sealer Using a Novel Sonic Agitation Device
}

\author{
S Anitha Rao ${ }^{1}$, Sunehra Sanam², Zaheer Ahmad ${ }^{3}$, CS Soonu ${ }^{4}$, Tummala Muralidhar ${ }^{5}$
}

\begin{abstract}
Aim: The aim of this in vitro study was to evaluate the efficacy of canal brush, Waterpik power flosser, and ultrasonic irrigation in removal of a sealer from the root canals using cone-beam computed tomography (CBCT).

Materials and methods: Forty-five extracted mandibular premolars were prepared and obturated. The samples were divided into three groups $(n=15)$. In each group, the sealer was removed using canal brush, Waterpik power flosser, and ultrasonic irrigation. All the samples underwent CBCT imaging. The amount of sealer was evaluated in CBCT sagittal sections and was scored. The maximum concentration of residual sealer was recorded.
\end{abstract}

Statistical analysis: Data were analyzed statistically using the IBM SPSS software version 20.0. Comparison of three groups with the amount of residual sealer was analyzed with the Kruskal-Wallis ANOVA and the Mann-Whitney $U$ test and the level of significance is set at $p<0.05$.

Results: In comparison among canal brush (mean $=3.7$ ), power flosser (mean $=2.7$ ), and ultrasonic irrigation ( mean $=2.3$ ), with $p$ value 0.0001 , power flosser showed enhanced efficiency in removing the sealer in apical third when compared to ultrasonic irrigation. The removal of the sealer with power flosser and ultrasonic irrigation in coronal and middle third showed no significant difference. However, in the case of canal brush, there was significant difference in the sealer removal. The efficiency of canal brush is less when compared to power flosser and ultrasonic irrigation in all the thirds.

Conclusion: The efficiency of sealer removal is more with both ultrasonic device and power flosser, but enhanced efficiency is seen with power flosser in apical third.

Keywords: Cone-beam computed tomography, Endodontic retreatment, Root filling materials, Ultrasonic irrigation, Waterpik power flosser. Journal of Operative Dentistry and Endodontics (2019): 10.5005/jp-journals-10047-0084

\section{INTRODUCTION}

The main objective of endodontic treatment is to eliminate infection from the root canal system and to prevent reinfection. However, the retreatment of endodontically treated teeth is a common procedure in endodontics. Various causes for endodontic failure include inadequate aseptic control, improper access cavity design, missed canals, and inadequate instrumentation. ${ }^{1}$ Ingle et al. ${ }^{2}$ reported that over two-thirds of these failures were related to incomplete cleaning and obturation of root canals and according to Harty et al. ${ }^{3}$ the majority of nonsurgical endodontic treatment failures is because of inadequate apical seal.

The presence of microorganisms and their toxic by-products in the root canal system is considered to be the main reason for treatment failure; ${ }^{4}$ the access to the areas of contamination inside the root canal system is crucial for successful retreatment. Hence, the thriving bacteria under the gutta-percha and sealer have to be removed. Among the different surgical or nonsurgical treatment concepts, orthograde retreatment is supposed to be the best treatment option. ${ }^{4}$ The main goal of nonsurgical root canal retreatment is to reestablish healthy periapical tissues, ${ }^{5}$ which can be fulfilled only if the filling material can be removed completely and the canal negotiated to the apical foramen. ${ }^{6-8}$

The retreatment procedure involves complete removal of the previous filling material and the sealer from the canal system as the first step to achieve effective disinfection prior to reobturation. \begin{tabular}{l}
\hline${ }^{1-5}$ Department of Conservative Dentistry and Endodontics, Mamata \\
Dental College, Khammam, Telangana, India
\end{tabular}

Corresponding Author: Sunehra Sanam, Department of Conservative Dentistry and Endodontics, Mamata Dental College, Khammam, Telangana, India, Phone: +91 9491493031, e-mail: Sunehrasanam1990@gmail.com

How to cite this article: Rao SA, Sanam S, Ahmad Z, et al. A Conebeam Computed Tomographic Evaluation of Removing Root Canal Sealer Using a Novel Sonic Agitation Device. J Oper Dent Endod 2019;4(2):72-79.

Source of support: Nil

Conflict of interest: None

Gutta-percha is the most commonly used root canal obturation material, in conjunction with a variety of sealers. ${ }^{9}$ It fulfills the criteria of being an ideal root filling by offering easy removal during retreatment procedures.

AH Plus (Dentsply DeTrey, Konstanz, Germany) is a widely used sealer in endodontic treatment. AH Plus sealer composition: Paste A: bisphenol-A epoxy resin, bisphenol-F epoxy resin, calcium tungstate, zirconium oxide, silica, iron oxide pigments. Paste B: dibenzyldiamine, aminoadamantane, tricyclodecane diamine, calcium tungstate, zirconium oxide, silica, silicone oil.

For proper removal of root canal filling, various techniques and materials have been proposed including hand files, heat-carrying

(c) The Author(s). 2019 Open Access This article is distributed under the terms of the Creative Commons Attribution 4.0 International License (https://creativecommons. org/licenses/by-nc/4.0/), which permits unrestricted use, distribution, and non-commercial reproduction in any medium, provided you give appropriate credit to the original author(s) and the source, provide a link to the Creative Commons license, and indicate if changes were made. The Creative Commons Public Domain Dedication waiver (http://creativecommons.org/publicdomain/zero/1.0/) applies to the data made available in this article, unless otherwise stated. 
instruments, chemical solvents, ultrasonic devices, lasers, and engine-driven instruments such as Gates Glidden drills, NiTi rotary instruments, and rotary instruments. ${ }^{10-14}$ However, no further data regarding the removal of sealer using different irrigation techniques are available until today.

Recently, several new irrigation systems and techniques have been developed. ${ }^{15}$ The Canal Brush (Roeko, Langenau, Germany) is a highly flexible plastic microbrush used in a dental handpiece with $600 \mathrm{rpm}$ in combination with manual irrigation. Several studies are differing in their conclusions ${ }^{16-18}$ regarding its effectiveness.

Passive ultrasonic irrigation (PUI) has been used in association with irrigants that contribute to a better cleaning of root canals. ${ }^{19}$ The tip of the instrument operates by not touching the dentinal walls and shaking the irrigating substances. Bubbles produced as a result burst and increase temperature and pressure resulting in a wave impact against root canal walls, thereby removing the debris. ${ }^{20}$

Waterpik Power Flosser is an activation device used for flossing the interdental areas (Fig. 1). It has a mechanism of action very similar as that of the EndoActivator. ${ }^{21}$ The less costly Waterpik Power Flosser system used in this study with GP points attached to the activator tips. Waterpik Power Flosser system (Waterpik Inc., Fort Collins, Colorado) also works on the principle of sonic activation. It also has a battery-driven handpiece and disposable flosser tips. ${ }^{21}$ These activator tips were fabricated by attaching GP points (Fig. 2). The Waterpik Power Flosser system has sonic mechanism of action similar to that of the EndoActivator and operates at a frequency of $1-6 \mathrm{kHz} .{ }^{21}$ In the study done by Shenoy et al., power flosser has been used to increase the efficacy of sodium hypochlorite. There is less literature review with Waterpik power flosser and there are no studies done with Waterpik power flosser for removal of calcium hydroxide.

The aim of this study was to investigate the efficiency of different irrigation techniques in removing the sealer from the root canal walls.

The null hypothesis tested was there was significant difference between cleaning efficiency of Waterpik power flosser and ultrasonic irrigation.

\section{Materials and Methods}

\section{Specimen Preparation and Root Canal Filling}

Forty-five extracted single-rooted mandibular premolars have been taken with approval from the ethical committee. The inclusion criteria include the teeth which are free of caries, cracks, fissures, and flaws were selected for this study and the exclusion criteria was any previous restorations, fractured teeth, and root canaltreated teeth were eliminated. The teeth were stored in a 3.0\% sodium hypochlorite $(\mathrm{NaOCl})$ solution for disinfection until further processing. They were then decoronated at the cementoenamel junction (Fig. 3) with a diamond disc under water coolant, leaving a root segment with a length of $16 \mathrm{~mm}$ to obtain standardization.

The root canals were explored with a size \#15 K-file (Mani, Tochigi, Japan) until the tip of the file was visible from the apex. The working length was determined by subtracting $1 \mathrm{~mm}$ from this length. The root canals were enlarged with ProTaper files to size F4 (Fig. 4), and each root canal was irrigated (Fig. 5) with saline and $1 \mathrm{~mL}$ of $3.0 \% \mathrm{NaOCl}$ simultaneously between each file, using a 27-gauge syringe. After through cleaning and shaping, the root canals were then flushed with 17\% EDTA (pH 7.3) (Merck KGaA, Darmstadt, Germany), followed by $3.0 \% \mathrm{NaOCl}$, for. Then, the root canals were dried with size \#40 paper points. Size \#40 gutta-percha master cones (Dentsply De Trey, Germany) were coated with AH Plus (Dentsply De Trey, Germany), and inserted into the root canal to the working length, while size \#20 and \#15 accessory gutta-percha cones were placed, using a finger spreader of corresponding guttapercha size of \#15 and \#20 to the point at which resistance was encountered. All root canals were filled using the lateral compaction technique (Fig. 6). A heated excavator was used to remove the excess gutta-percha, and coronal access was sealed with Cavit (3M ESPE, St Paul, MN, USA). The specimens were then incubated for 1 week at $37^{\circ} \mathrm{C}$ with $100 \%$ humidity to allow complete setting. All specimens were fixed in wax plates and scanned using cone-beam computed tomography (CBCT) (3D Accuitoma 170, Morita, Tokyo, Japan) for the preoperative morphometric evaluation.

\section{Retreatment Technique}

The roots were randomly divided into three groups $(n=15)$. The 2-mm coronal part of the root canal filling material was removed from all canals with a \#3 Gates glidden drill to facilitate the initial penetration of the files into the filling material. Gutta-percha points that were removed using the ProTaper Universal retreatment kit (Dentsply Maillefer, Ballaigues, Switzerland) include D1 (30/0.09), D2 (25/0.08), and D3 (20/0.07) files with different tapers and tip diameters that are specifically designed to remove the root canal obturation material from the coronal, middle, and apical thirds of the canals, respectively. ${ }^{22}$

The following irrigation techniques were applied:

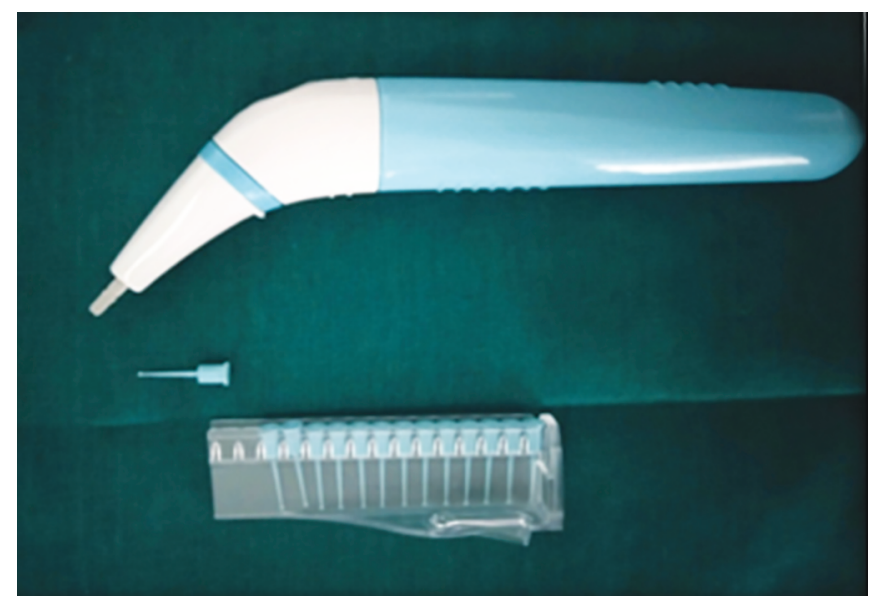

Fig. 1: Waterpik Power Flosser

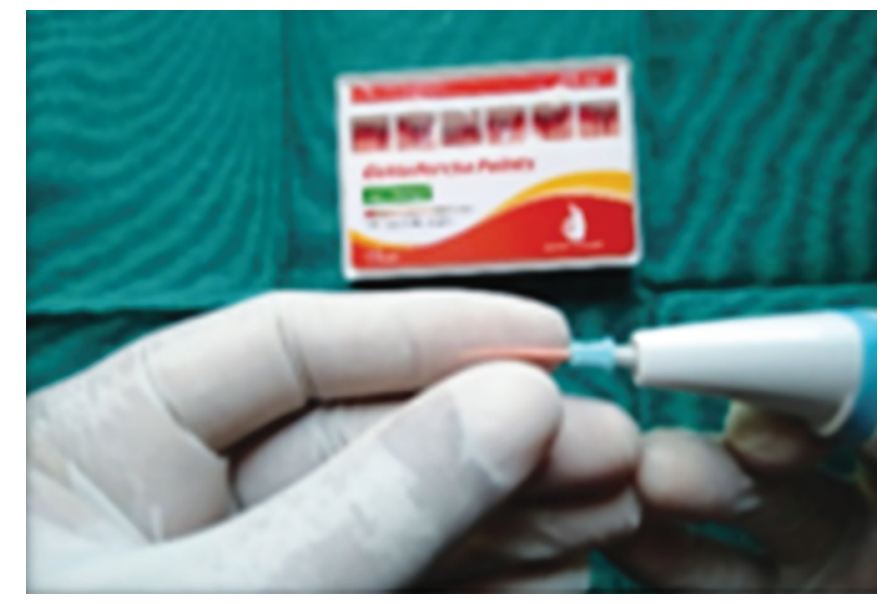

Fig. 2: Gutta percha points 


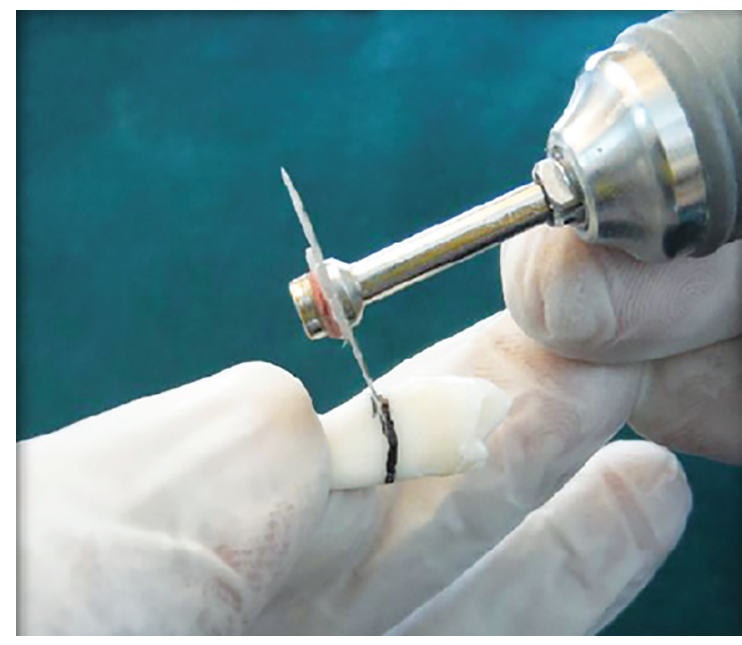

Fig. 3: Decoronation at cementoenamel junction

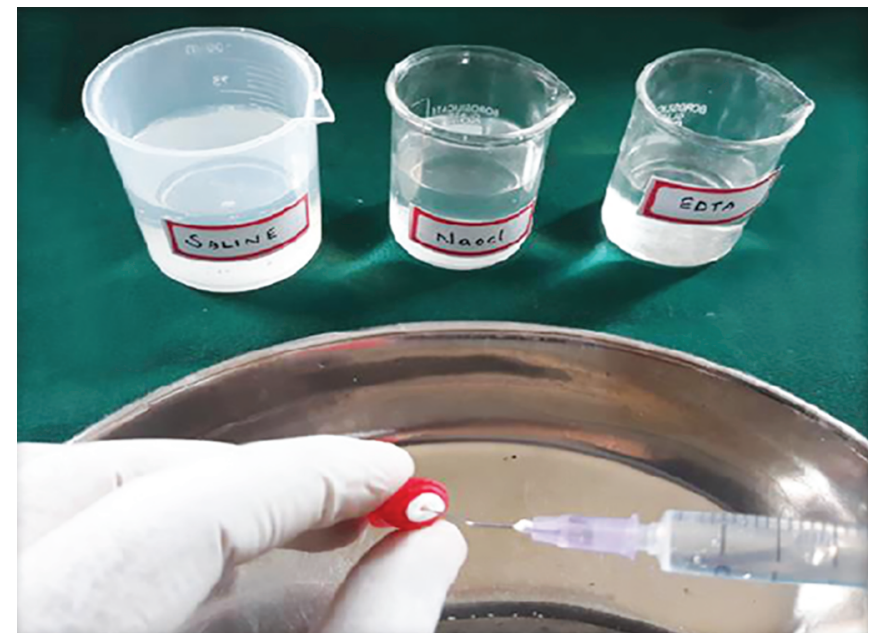

Fig. 5: Irrigation with saline, EDTA and sodium hypochlorite

Teeth were then randomly distributed into three groups according to the irrigation regimen used:

Group I: $3.0 \% \mathrm{NaOCl}$ agitated with canal brush with a 2-3 $\mathrm{mm}$ up and down motion after advancing the brush to working length for 30 seconds (Fig. 7).

Group II: $3.0 \% \mathrm{NaOCl}$ agitated with Waterpik Power Flosser for 3 minutes (Fig. 8).

Group III: $3.0 \% \mathrm{NaOCl}$ agitated with ultrasonic activation as recommended by the manufacturer with a file size 15 inserted (Fig. 9) for 30 seconds.

Then postretreatment technique $C B C T$ images were taken and evaluated in axial, coronal, and sagittal planes. The coronal, middle, and apical thirds of the root were evaluated for the percentage of the residual sealer material on the walls. Furthermore, sagittal CBCT cross-sections were used for observational scoring of the residual sealer material based on the scoring system introduced by Somma et al. ${ }^{23}$ as follows: score 1-no residual material or a small amount of residual material on the dentin surface $(<25 \%)$; score 2 -some residual debris on the dentin surface (25-50\%); score 3-a moderate amount of debris on the dentin surface (50-75\%); score 4-a large amount of debris on the dentin surface ( $>75 \%)$.

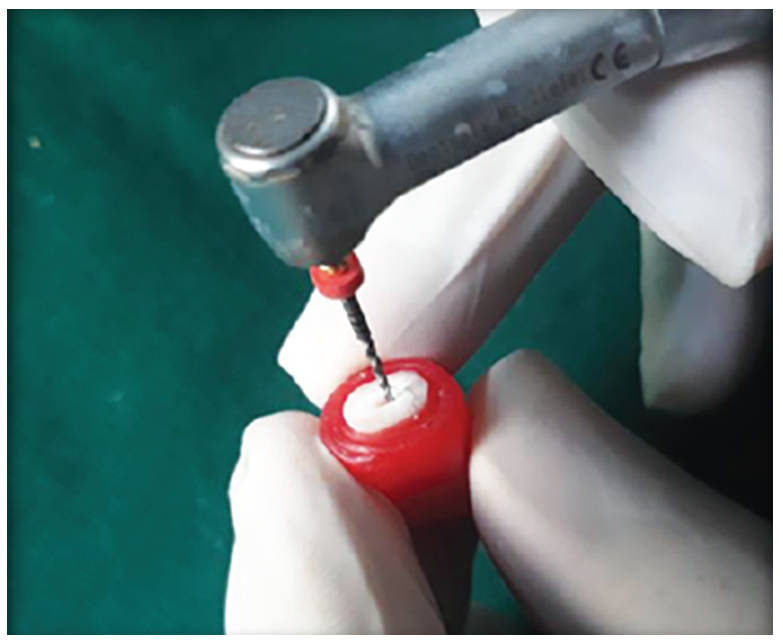

Fig. 4: Root canal preparation using ProTaper files to size F4

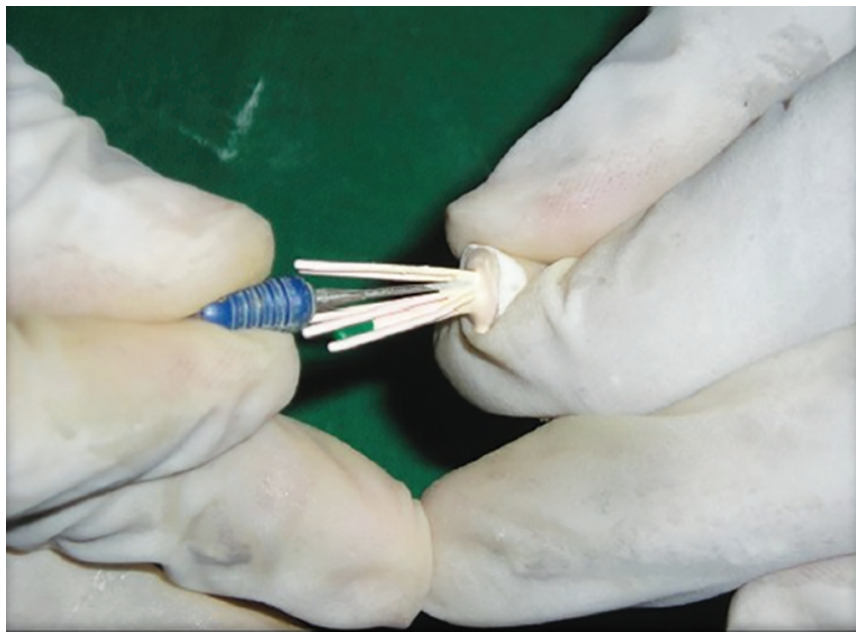

Fig. 6: Obturation using lateral compaction technique

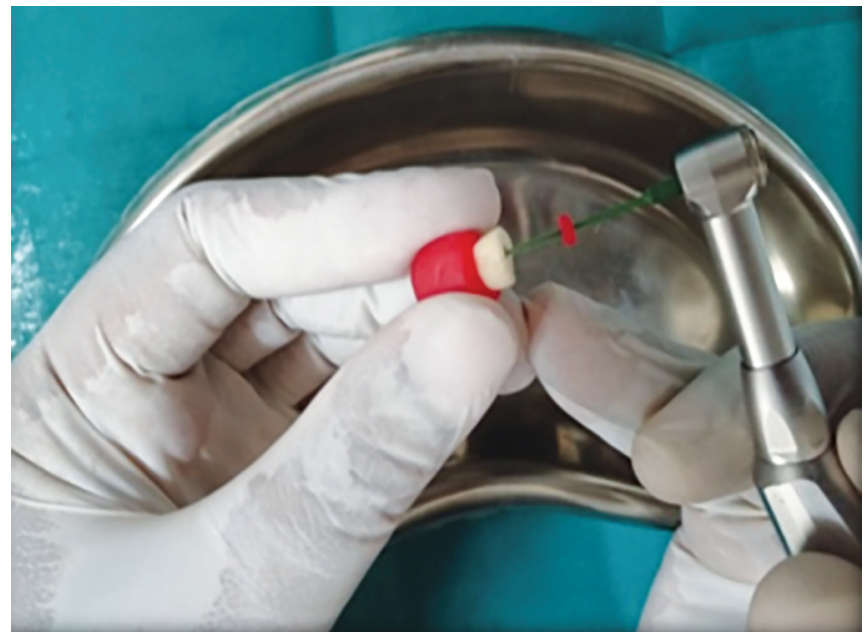

Fig. 7: $3.0 \% \mathrm{NaOCl}$ agitated with canal brush

\section{Statistical Analysis}

Data were analyzed statistically using the IBM SPSS software version 20.0. Comparison of three groups with the amount of 


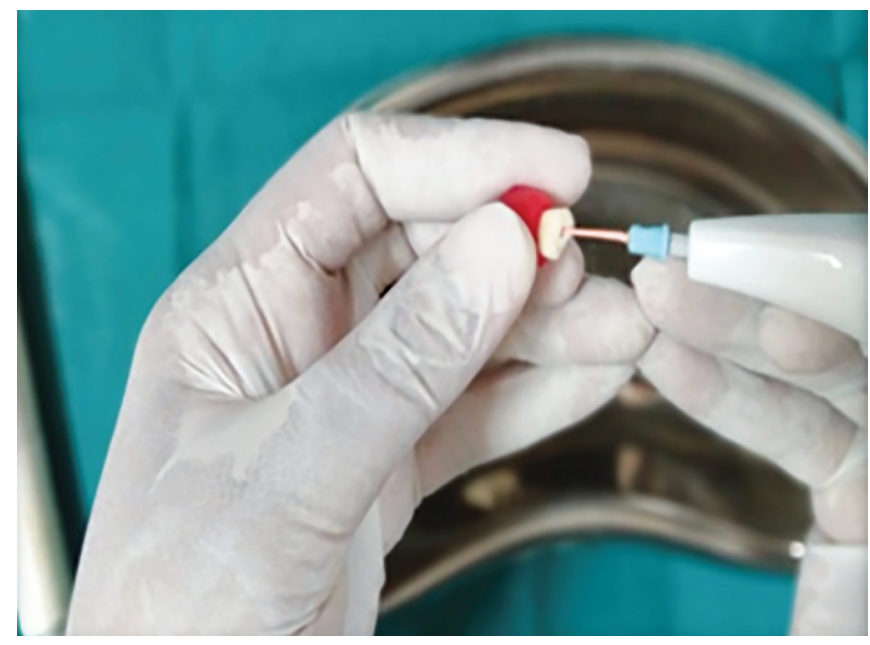

Fig. 8: $3.0 \% \mathrm{NaOCl}$ agitated with Waterpik Power Flosser

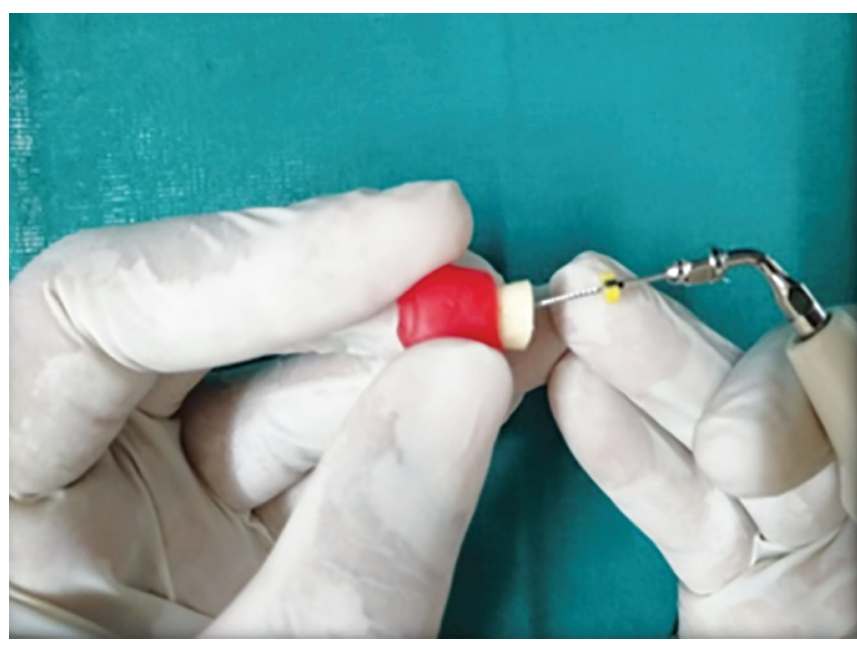

Fig. 9: 3.0\% NaOCl agitated with ultrasonic activation

Table 1: Comparison of three groups with amount of residual sealer in each side by Kruskal-Wallis ANOVA and Mann-Whitney $U$ test

\begin{tabular}{|c|c|c|c|c|c|c|}
\hline Sides & Groups & Mean & $S D$ & Median & $I Q R$ & Mean rank \\
\hline \multirow[t]{9}{*}{ Apical } & Canal brush (CB) & 3.5 & 0.7 & 4.0 & 0.5 & 33.20 \\
\hline & Power flosser (PF) & 2.7 & 0.5 & 3.0 & 0.5 & 15.50 \\
\hline & Ultrasonic irrigation (UI) & 2.3 & 0.9 & 2.0 & 0.5 & 20.30 \\
\hline & $H$ value & 16.8580 & & & & \\
\hline & $p$ value & $0.0001^{*}$ & & & & \\
\hline & \multicolumn{6}{|c|}{ Pairwise comparisons by Mann-Whitney $U$ test } \\
\hline & CB vs $P F$ & $p=0.0006^{*}$ & & & & \\
\hline & CB vs UI & $p=0.0035^{*}$ & & & & \\
\hline & PF vs UI & $p=0.2134$ & & & & \\
\hline \multirow[t]{9}{*}{ Middle } & Canal brush (CB) & 2.3 & 0.5 & 2.0 & 0.5 & 31.67 \\
\hline & Power flosser (PF) & 2.0 & 0.5 & 2.0 & 0.0 & 17.80 \\
\hline & Ultrasonic irrigation (UI) & 1.8 & 0.8 & 2.0 & 0.5 & 19.53 \\
\hline & $\mathrm{H}$ value & 12.2320 & & & & \\
\hline & $p$ value & $0.0020^{*}$ & & & & \\
\hline & \multicolumn{6}{|c|}{ Pairwise comparisons by Mann-Whitney $U$ test } \\
\hline & CB vs PF & $p=0.0030^{*}$ & & & & \\
\hline & CB vs UI & $p=0.0153^{*}$ & & & & \\
\hline & PF vs UI & $p=0.7875$ & & & & \\
\hline \multirow[t]{9}{*}{ Coronal } & Canal brush (CB) & 2.6 & 0.0 & 3.0 & 0.5 & 29.03 \\
\hline & Power flosser (PF) & 2.1 & 0.7 & 2.0 & 0.5 & 22.60 \\
\hline & Ultrasonic irrigation (UI) & 1.5 & 0.5 & 1.0 & 0.5 & 17.37 \\
\hline & $H$ value & 7.0940 & & & & \\
\hline & $p$ value & $0.0290^{*}$ & & & & \\
\hline & \multicolumn{6}{|c|}{ Pairwise comparisons by Mann-Whitney $U$ test } \\
\hline & $C B$ vs $P F$ & $p=0.1914$ & & & & \\
\hline & CB vs UI & $p=0.0144^{*}$ & & & & \\
\hline & PF vs UI & $p=0.2902$ & & & & \\
\hline
\end{tabular}

${ }^{*} p<0.05$

residual sealer was analyzed with the Kruskal-Wallis ANOVA and the Mann-Whitney $U$ test and the level of significance is set at $p<0.0$ (Tables 1 to 3 ).

\section{RESULTS}

The CBCT analysis of all the groups has been done after removing the sealer (Fig. 10). In comparison with canal brush, power flosser, and ultrasonic irrigation, power flosser showed enhanced efficiency in removing the sealer in apical third (Fig. 11) when compared to ultrasonic irrigation (Fig. 12). The removal of the sealer with power flosser and ultrasonic irrigation in coronal and middle third showed no significant difference. However, in the case of canal brush there was significant difference in the sealer removal. The efficiency of canal brush is less when compared to power flosser and ultrasonic 
A Cone-beam Computed Tomographic Evaluation of Removing Root Canal Sealer Using a Novel Sonic Agitation Device

Table 2: Comparison of three sides with amount of residual sealer in each group by Kruskal-Wallis ANOVA and Mann-Whitney U test

\begin{tabular}{|c|c|c|c|c|c|c|}
\hline Groups & Sides & Mean & $S D$ & Median & $I Q R$ & Mean rank \\
\hline \multirow[t]{9}{*}{ Canal brush } & Apical & 3.5 & 0.7 & 4.0 & 0.5 & 32.27 \\
\hline & Middle & 2.3 & 0.5 & 2.0 & 0.5 & 21.73 \\
\hline & Coronal & 2.6 & 0.5 & 3.0 & 0.5 & 15.00 \\
\hline & $H$ value & 14.7200 & & & & \\
\hline & $p$ value & $0.0010^{*}$ & & & & \\
\hline & \multicolumn{6}{|c|}{ Pairwise comparisons by Mann-Whitney $U$ test } \\
\hline & Apical vs middle & $p=0.0075^{*}$ & & & & \\
\hline & Apical vs coronal & $p=0.0020^{*}$ & & & & \\
\hline & Middle vs coronal & $p=0.0591$ & & & & \\
\hline \multirow[t]{9}{*}{ Power flosser } & Apical & 2.7 & 0.5 & 3.0 & 0.5 & 28.17 \\
\hline & Middle & 2.0 & 0.5 & 2.0 & 0.0 & 22.13 \\
\hline & Coronal & 2.1 & 0.7 & 2.0 & 0.5 & 18.70 \\
\hline & $H$ value & 5.2020 & & & & \\
\hline & $p$ value & 0.0740 & & & & \\
\hline & \multicolumn{6}{|c|}{ Pairwise comparisons by Mann-Whitney $U$ test } \\
\hline & Apical vs middle & $p=0.1777$ & & & & \\
\hline & Apical vs coronal & $p=0.0620$ & & & & \\
\hline & Middle vs coronal & $p=0.4186$ & & & & \\
\hline \multirow[t]{9}{*}{ Ultrasonic irrigation } & Apical & 2.3 & 0.0 & 2.0 & 0.5 & 32.20 \\
\hline & Middle & 1.8 & 0.8 & 2.0 & 0.5 & 23.33 \\
\hline & Coronal & 1.5 & 0.5 & 1.0 & 0.5 & 13.47 \\
\hline & $H$ value & 17.7570 & & & & \\
\hline & $p$ value & $0.0001^{*}$ & & & & \\
\hline & \multicolumn{6}{|c|}{ Pairwise comparisons by Mann-Whitney $U$ test } \\
\hline & Apical vs middle & $p=0.0538$ & & & & \\
\hline & Apical vs coronal & $p=0.0001^{*}$ & & & & \\
\hline & Middle vs coronal & $p=0.0327^{*}$ & & & & \\
\hline
\end{tabular}

${ }^{*} p<0.05$

Table 3: Comparison of three groups with amount of residual sealer in each side

\begin{tabular}{|c|c|c|c|c|c|c|c|}
\hline Sides & Canal brush & (\%) & Power flosser & (\%) & Ultrasonic irrigation & (\%) & Total \\
\hline \multicolumn{8}{|l|}{ Coronal } \\
\hline Score 1 & 0 & 0.00 & 0 & 0.00 & 0 & 0.00 & 0 \\
\hline Score 2 & 2 & 13.33 & 10 & 66.67 & 6 & 40.00 & 18 \\
\hline Score 3 & 4 & 26.67 & 5 & 33.33 & 9 & 60.00 & 18 \\
\hline Score 4 & 9 & 60.00 & 0 & 0.00 & 0 & 0.00 & 9 \\
\hline \multicolumn{8}{|c|}{ Chi-square $=25.6671, p=0.0004^{*}$} \\
\hline \multicolumn{8}{|l|}{ Middle } \\
\hline Score 1 & 0 & 0.00 & 2 & 13.33 & 3 & 20.00 & 5 \\
\hline Score 2 & 4 & 26.67 & 11 & 73.33 & 8 & 53.33 & 23 \\
\hline Score 3 & 11 & 73.33 & 2 & 13.33 & 4 & 26.67 & 17 \\
\hline Score 4 & 0 & 0.00 & 0 & 0.00 & 0 & 0.00 & 0 \\
\hline \multicolumn{8}{|c|}{ Chi-square $=13.900, p=0.0076^{*}$} \\
\hline \multicolumn{8}{|l|}{ Apical } \\
\hline Score 1 & 2 & 13.33 & 6 & 40.00 & 8 & 53.33 & 16 \\
\hline Score 2 & 9 & 60.00 & 6 & 40.00 & 7 & 46.67 & 22 \\
\hline Score 3 & 2 & 13.33 & 3 & 20.00 & 0 & 0.00 & 5 \\
\hline Score 4 & 2 & 13.33 & 0 & 0.00 & 0 & 0.00 & 2 \\
\hline \multicolumn{8}{|c|}{ Chi-square $=10.9362, p=0.0904$} \\
\hline Total & 15 & 100.00 & 15 & 100.00 & 15 & 100.00 & 45 \\
\hline
\end{tabular}




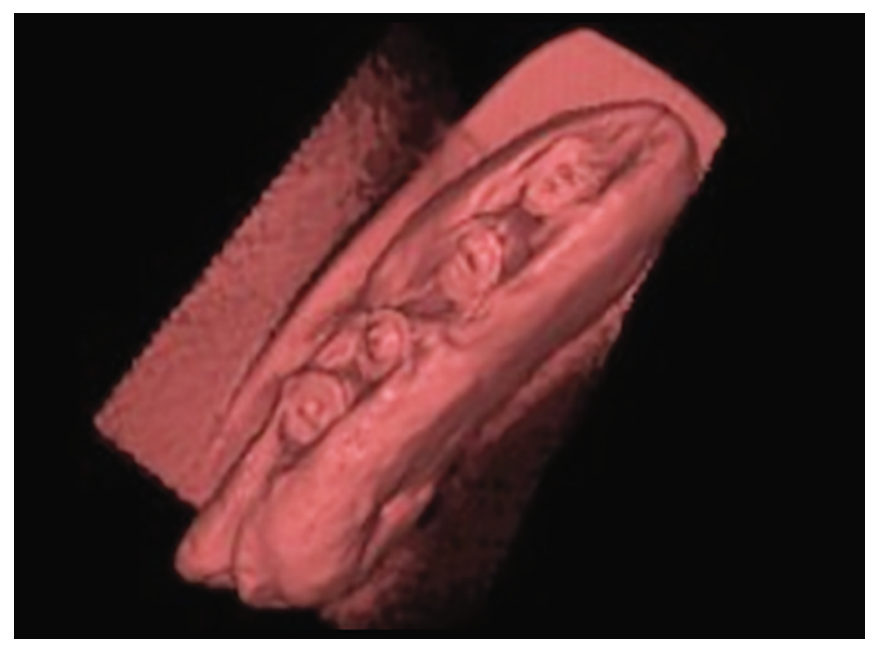

Fig. 10: Cone-beam computed tomography analysis

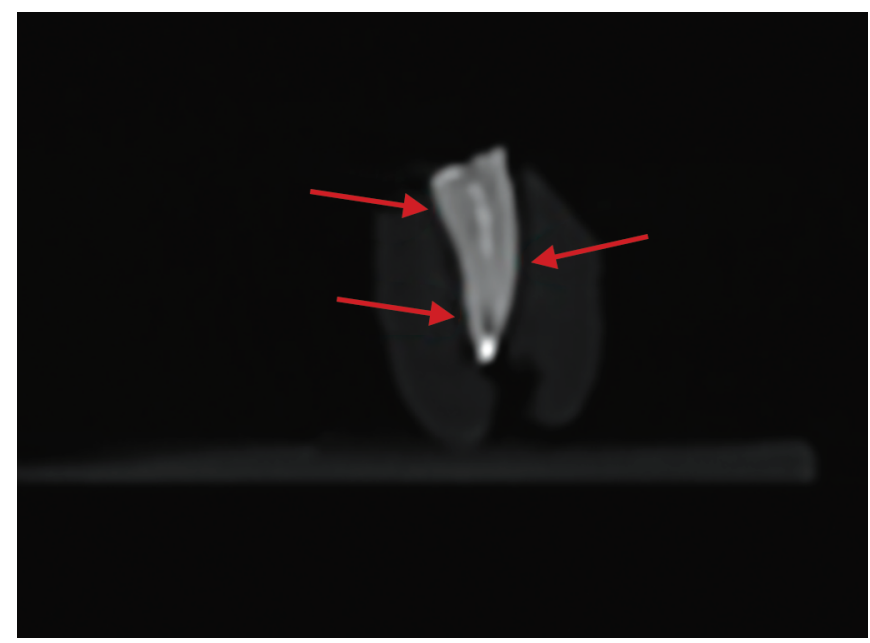

Fig. 12: Ultrasonic irrigation

irrigation in all the thirds (Fig. 13). In comparison with power flosser, ultrasonic irrigation and canal brush the power flosser showed enhanced irrigation which is not significantly different from ultrasonic irrigation where as canal brush showed to be less efficient than other two groups (Figs 14 and 15).

\section{Discussion}

The aim of endodontic retreatment is healing or prevention of apical periodontitis by elimination of the persisting intracanal infection. In retreatment cases, this can only be achieved following complete cleaning of the complex root canal system from filling materials. There is no reliable and evidence-based recommendation for the removal of root canal sealers.

The design of the present study was chosen following the methodology of previous studies on removal of intracanal materials and efficacy of irrigation protocols. ${ }^{24}$ Retreatment without solving agents often causes smearing, which leads to faster-to-seek results. ${ }^{25}$ Based on this study protocol, the efficiency of canal brush cannot be confirmed. Salman et al. ${ }^{18}$ determined the efficiency of a sonically activated canal brush and found improved debridement in all thirds. In the power flosser and the canal brush groups and to some extent even in the PUI group, cleaning efficiency is a result

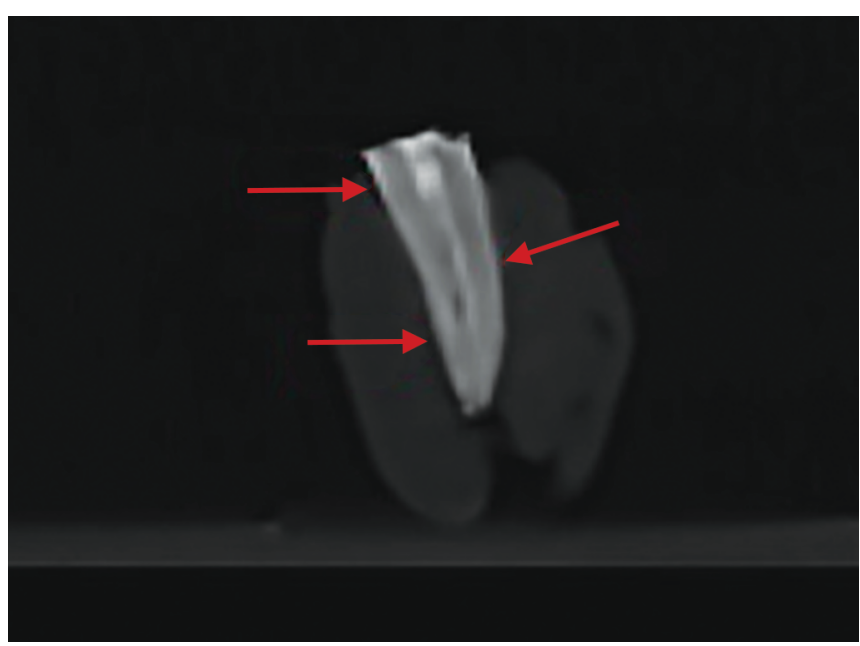

Fig. 11: Power flosser with enhanced efficiency in removing sealer in apical third

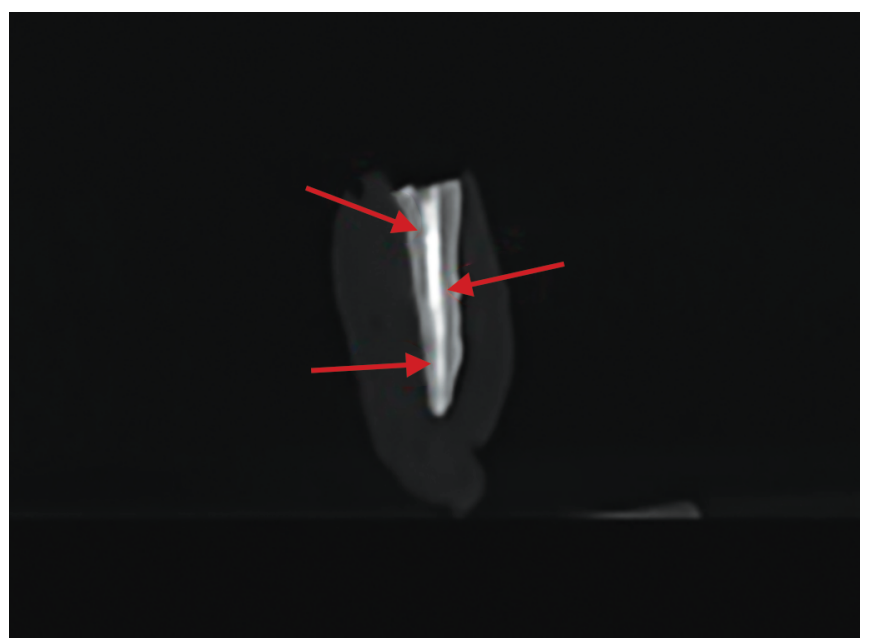

Fig. 13: Less efficiency of canal brush

of hydrodynamics of the irrigant caused by the respective device and mechanical action onto the root canal wall by the device itself.

The results of the present study justify the conclusion that the shear strengths generated during irrigation were not high enough to remove the sealer from the grooves. These findings are in contrast to findings for the removal of endodontic medicaments such as calcium hydroxide or ledermix, which at least could be partially dissolved and removed from root canal walls. ${ }^{20}$ Previous studies suggested that removing all obturating materials from the root canal space is very difficult, and some traces of GP and sealer remain inadvertently in the canal after instrumentation regardless of the technique used. For the removal of the sealer, irrigation with sodium hypochlorite alone was not effective; therefore, a combination of chemical and mechanical methods seems to be necessary. A widely used removal technique uses irrigants and hand instruments inserted onto working length. ${ }^{16}$

Advanced techniques and devices for root canal irrigation and disinfection have been introduced recently. Some of these new instruments, such as the Self Adjusting File (ReDent Nova, Raanana, Israel), photon-initiated photoacoustic streaming, Canal Brush Coltene/Whaledent, Altstatten, Switzerland), laser systems, EndoActivator (Dentsply, Tulsa, USA), EndoVac (Kerr Dental, Orange, 


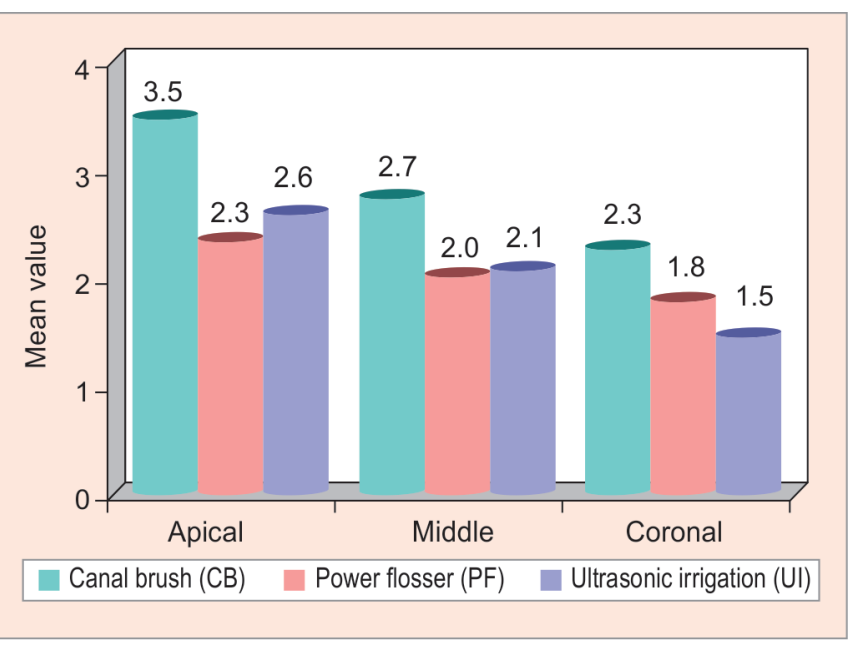

Fig. 14: Comparison of three groups with amount of residual sealer in each side

USA), RinsEndo (Durr-Dental, Bietingheim-Bissingen, Germany), Gentle Wave system (Sonendo, Laguna Hills, USA), and XP Endo finisher (FKG, Chaux-de-Fonds, Switzerland) have been used for removal of intracanal medicaments. The results concerning the efficacy of these devices and techniques are controversial.

Limited comparable data are available for the sonic agitation of irrigation in root canals. These findings are a result of ultrasonic agitation of the irrigation systems in the root canals. Several studies have shown that the apical third of the root canal is the most difficult to clean (Walters et al., ${ }^{26}$ Gutarts et al., ${ }^{27}$ Passarinho-Neto et al.). ${ }^{28}$ The positive effect of sonically agitated irrigation may be explained by sonically induced acoustic cavitation, acoustic microstreaming, and heat. ${ }^{20}$ Additionally, activation of irrigants may further improve removal of the intracanal dressing. Manual push and pull movements using a fitted master gutta-percha cone (manual-dynamic irrigation) were shown to improve root canal cleanliness but may harbor the risk of packing the sealer apically and onto the canal surface.

The CanalBrush (Roeko, Langenau, Germany) is a highly flexible plastic microbrush used in a dental handpiece with $600 \mathrm{rpm}$ in combination with manual irrigation. Nevertheless, the study design could not exclude the possibility of a mechanical impact from the soft, flexible bristles of the CanalBrush. There is the possibility that an inadvertent, gentle touch of the polypropylene bristles against the root canal walls improved removal of the sealer. The 30 -second agitation time was investigated by Sabins et al. ${ }^{29}$ This 30 -second agitation time avoids the fracture bristles so that this time period makes the daily practice easy. Although the manufacturer reported deformations when the CanalBrush was used with greater speeds (recommended 500-600 rpm), in this study, no fractures were found in the bristles or brush. The short sonication duration of 30 seconds per root canal makes this a viable procedure for daily practice.

The ultrasonic endodontic retreatment tip E-7, E-3 Max $0.6 \mathrm{~mm}$ diameter at tip and $16 \mathrm{~mm}$ length) was used for the removal of the root canal filing material. ${ }^{30}$

Waterpik power flosser is an activation device used for flossing interdental areas. Its mechanism of action includes irrigation by sonic agitation by creating nodes along the root canal wall. It is similar to endoactivator and the tips are interchangeable. It is more economical. $^{21}$

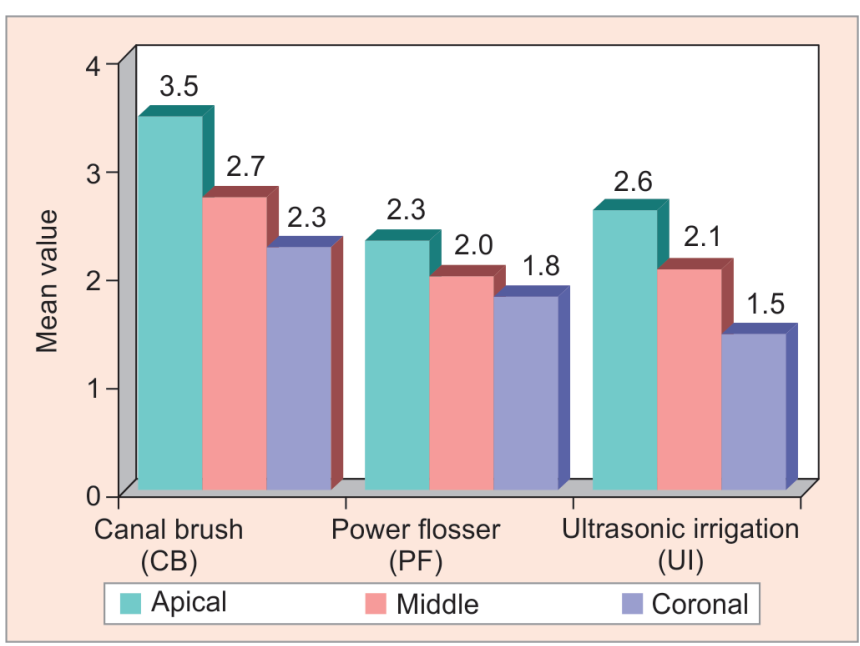

Fig. 15: Comparison of three sides with amount of residual sealer in each group

Passive ultrasonic irrigation can be effective in curved canals and can be used with a small file oscillating freely in the root canal to induce power acoustic microstreaming. It removes more organic tissue, planktonic bacteria, and dentine debris from the root canal. ${ }^{20}$ Endovac is a true apical negative pressure irrigation system. It enables irrigation to full working length. It creates a powerful current force to pump disinfecting irrigants throughout the entire canal system. ${ }^{31}$ Self-adjusting file system technology allows for effective cleaning of the root canals including oval-shaped. Its technology uses a new concept for effective cleaning in which a uniform layer of dentin is removed, thus avoiding unnecessary excessive removal of sound dentin. ${ }^{32}$

Splitting is an invasive method and can spread the remaining filling materials. Radiography and digitized images provide twodimensional information from three-dimensional structures. Computed tomography $(\mathrm{CT})$ has been used for three-dimensional evaluation of the root canal system and does not require the destruction of the teeth. ${ }^{33,34}$

Computed tomography has subsequently refined to incorporate a helical or spiral motion, fan-shaped bean which enables fast scan times that provide high-quality images than in spiral CT. Conebeam computed tomography makes clinical decision making easier and more precise, patient treatment decision more accurate, and visualization of X-ray data more meaningful. ${ }^{35}$

Other methods of assessment include radiographic methods and microscopic methods. The null hypothesis was rejected as there was no significant difference between Waterpik power flosser and ultrasonic irrigation.

\section{Conclusion}

Within the limitations of this study, the efficiency of sealer removal is more with both ultrasonic device and power flosser, but enhanced efficiency is seen with power flosser in apical third. The removal of the sealer with power flosser and ultrasonic irrigation in coronal and middle third showed no significant difference. However, in the case of canal brush there was significant difference in the sealer removal. The efficiency of canal brush is less when compared to power flosser and ultrasonic irrigation in all the thirds of the root canal. 


\section{REFERENCES}

1. Sundqvist G, Figdor D, Persson S, et al. Microbiologic analysis of teeth with failed endodontic treatment and the outcome of conservative re-treatment. Oral Surg Oral Med Oral Pathol 1998;85(1):86-93. DOI: 10.1016/s1079-2104(98)90404-8.

2. Ingle Jl, Beveridge EE, GlicK DH, et al. Modern endodontic therapy. In: Ingle JI, Bakland LK. Endodontics. 4th ed., Philadelphia: Lee \& Febiger; 1994. 33.

3. Harty FJ, Parkins BJ, Wengraf AM. Success rate in root canal therapy: A retrospective study of conventional cases. Br Dent J 1970a;28(2): 65-70. DOI: $10.1038 /$ sj.bdj.4802429.

4. Zehnder M, Paque F. Disinfection of the root canal system during root canal re-treatment. Endod Top 2011;19(1):58-73. DOI: 10.1111/j.16011546.2011.00254.x.

5. Schirrmeister JF, Meyer KM, Hermanns P, et al. Effectiveness of hand and rotary instrumentation for removing a new synthetic polymer-based root canal obturation material (Epiphany) during retreatment. Int Endod J 2006;39(2):150-156. DOI: 10.1111/j.13652591.2006.01066.x.

6. Bergenholtz G, Lekholm U, Milthon R, et al. Retreatment of endodontic fillings. Scand J Dent Res 1979;87(3):217-224. DOI: 10.1111/j.1600-0722.1979.tb00675.x.

7. Friedman S, Stabholz A. Endodontic retreatment case selection and technique. Part 2: Treatment planning for retreatment. J Endod 1988;14(12):607-614. DOI: 10.1016/S0099-2399(88)80058-X.

8. Friedman S, Stabholz A, Tamse A. Endodontic retreatment case selection and technique. 3. Retreatment techniques. J Endod 1990;16(11):543-649. DOI: 10.1016/s0099-2399(07)80219-6.

9. Kratchman SI. Obturation of the root canal system. Dent Clin North Am 2004;48(1):203-215. DOI: 10.1016/j.cden.2003.12.004.

10. Reddy S, Neelakantan P, Saghiri MA, et al. Removal of guttapercha/ zinc-oxide-eugenol sealer or gutta-percha/epoxy resin sealer from severely curved canals: an in vitro study. Int J Dent 2011;2011:541831. DOI: $10.1155 / 2011 / 541831$.

11. Sae-Lim V, Rajamanickam I, Lim BK, et al. Effectiveness of ProFile .04 taper rotary instruments in endodontic retreatment. J Endod 2000;26(2):100-104. DOI: 10.1097/00004770-20000200000010.

12. Tachinami $\mathrm{H}$, Katsuumi I. Removal of root canal filling materials using Er:YAG laser irradiation. Dent Mater J 2010;29(3):246-252. DOI: 10.4012/dmj.2008-079.

13. Zmener O, Pameijer $\mathrm{CH}$, Banegas $\mathrm{G}$. Retreatment efficacy of hand versus automated instrumentation in oval-shaped root canals: an ex vivo study. Int Endod J 2006;39(7):521-526. DOI: 10.1111/j.13652591.2006.01100.x.

14. Hulsmann M, Stotz S. Efficacy, cleaning ability and safety of different devices for gutta-percha removal in root canal retreatment. Int Endod J 1997;30(4):227-233. DOI: 10.1111/j.1365-2591.1997. tb00702.x.

15. Gu LS, Kim JR, Ling J, et al. Review of contemporary irrigant agitation techniques and devices. J Endod 2009;35(6):791-804. DOI: 10.1016/ j.joen.2009.03.010.

16. Weise $M$, Roggendorf $M J$, Ebert J, et al. Four methods for cleaning simulated lateral extensions of curved root canals: a SEM evaluation. Int Endod J 2007;40:991-992.

17. Garip Y, Sazak H, Gunday M, et al. Evaluation of smear layer removal after use of a canal brush: an SEM study. Oral Surg Oral Med Oral Pathol Oral Radiol Endod 2010;110(2):62-66. DOI: 10.1016/ j.tripleo.2010.02.037.
18. Salman MI, Baumann MA, Hellmich M, et al. SEM evaluation of root canal debridement with sonicare CanalBrush irrigation. Int Endod J 2010;43(5):363-369. DOI: 10.1111/j.1365-2591.2009.01675.x.

19. Mozo S, Llena C, Chieffi N, et al. Effectiveness of passive ultrasonic irrigation in improving elimination of smear layer and opening dentinal tubules. J Clin Exp Dent 2014;6(1):47-52.

20. van der Sluis $\mathrm{LW}$, Versluis $\mathrm{M}, \mathrm{Wu} \mathrm{MK}$, et al. Passive ultrasonic irrigation of the root canal: a review of the literature. Int Endod J 2007;40(6): 415-426. DOI: 10.1111/j.1365-2591.2007.01243.x.

21. Shenoy A, Mandava P, Bolla N, et al. Antibacterial efficacy of sodium hypochlorite with a novel sonic agitation device. Indian J Dent RS 2013;24(5):537-541. DOI: 10.4103/0970-9290.123361.

22. Giuliani V, Cocchetti R, Pagavino G. Efficacy of ProTaper universal retreatment files in removing filling materials during root canal retreatment. J Endod 2008;34(11):1381-1384. DOI: 10.1016/ j.joen.2008.08.002.

23. Somma F, Cammarota G, Plotino G, et al. The effectiveness of manual and mechanical instrumentation for the retreatment of three different root canal filling materials. J Endod 2008;34(4):466-469. DOI: 10.1016/j.joen.2008.02.008.

24. Lee SJ, Wu MK, Wesselink PR. The effectiveness of syringe irrigation and ultrasonics to remove debris from simulated irregularities within prepared root canal walls. Int Endod J 2004;37(10):672-678. DOI: 10.1111/j.1365-2591.2004.00848.x.

25. Ma J, Al-Ashaw AJ, Shen Y, et al. Efficacy of ProTaper universal rotary retreatment system for gutta-percha removal from oval root canals: a micro-computed tomography study. J Endod 2012;38(11):1516-1520. DOI: 10.1016/j.joen.2012.08.001.

26. Walters MJ, Baumgartner JC, Marshall JG. Efficacy of irrigation with rotary instrumentation. J Endod 2002;28(12):837-839. DOI: 10.1097/00004770-200212000-00011.

27. Gutarts R, Nusstein J, Reader A, et al. In vivo debridement efficacy of ultrasonic irrigation following handrotary instrumentation. J Endod 2005;3(3):166-171. DOI: 10.1097/01.don.0000137651. 01496.48.

28. Passarinho-Neto JG, Marchesan MA, Ferreira RB, et al. In vitro evaluation of endodontic debris removal as obtained by rotary instrumentation coupled with ultrasonic irrigation. Aust Endod J 2006;32(3):123-128. DOI: 10.1111/j.1747-4477.2006.00035.x.

29. Sabins R, Johnson J, Hellstein J. A comparison of the cleaning efficacy of short-term sonic and ultrasonic passive irrigation after hand instrumentation in molar root canals. J Endod 2003;29(10):674-678. DOI: 10.1097/00004770-200310000-00016.

30. Kasam S, Mariswamy AB. Efficacy of different methods for removing root canal filling material in retreatment - An In-vitro study. JJ Clin Diagn Res 2016;10(6):6-10.

31. Negative pressure irrigation system. Endovac J Endod 2010;36(4): 745-750. DOI: 10.1016/j.joen.2009.11.022.

32. The self adjusting file system; an evidence based update. J Conserve Dent 2014;17(5):401-419. DOI: 10.4103/0972-0707.139820.

33. Barletta FB, Rahde Nde M, Limongi O, et al. In vitro comparative analysis of 2 mechanical techniques for removing gutta-percha during retreatment. J Can Dent Assoc 2007;73(1):65.

34. Hammad M, Qualtrough A, Silikas N. Three-dimensional evaluation of effectiveness of hand and rotary instrumentation for retreatment of canals filled with different materials. J Endod 2008;34(11):1370-1373. DOI: 10.1016/j.joen.2008.07.024.

35. Luke AM, Shetty KP, Satish SV. Comparison of spiral computed tomography and computed tomography. J Indian Acad Oral Med Radiol 2013;25(3):173-177. 